\title{
Predictors of Carotid Intima-Media Thickness and Plaque Progression in a Chinese Population
}

\author{
Ling-Chun Huang ${ }^{1}$, Ruey-Tay Lin ${ }^{1,2}$, Chien-Fu Chen ${ }^{1,2}$, Chun-Hung Chen ${ }^{1}$, Suh-Hang Hank Juo ${ }^{3,4}$ and \\ Hsiu-Fen Lin ${ }^{1,2}$ \\ ${ }^{1}$ Department of Neurology, Kaohsiung Medical University Hospital, Kaohsiung, Taiwan \\ ${ }^{2}$ Department of Neurology, College of Medicine, Kaohsiung Medical University, Kaohsiung, Taiwan \\ ${ }^{3}$ Department of Medical Research, Kaohsiung Medical University Hospital, Kaohsiung, Taiwan \\ ${ }^{4}$ Department of Medical Genetics, College of Medicine, Kaohsiung Medical University, Kaohsiung, Taiwan
}

Aim: Atherosclerotic diseases are the leading cause of death worldwide. Longitudinal changes in carotid intima-media thickness (IMT) and plaque are being increasingly used as markers of atherosclerosis progression and may predict future cardiovascular events. This study aimed to investigate the predictors of carotid IMT and plaque progression in a Chinese population and to determine whether these predictors differ by gender.

Methods: Segment-specific carotid IMT and plaque were measured in 712 stroke- and myocardial infarction-free subjects at baseline and after an average interval of $4.3 \pm 0.9$ years. Multivariate linear regression and logistic regression analyses were conducted to investigate the predictive effect of age, gender, and cardiovascular risk factors on carotid IMT and plaque progression. Gender-specific analyses were also performed.

Results: Overall, age and smoking were predictors of common carotid artery IMT progression (adjusted $p<0.001$ and $p=0.045$, respectively). Age, hypertension, and use of antihypertensive medication were predictors of bifurcation IMT progression (adjusted $p<0.001, p=0.033$, and $p<0.001$, respectively). The use of antihypertensive medication was associated with less annual IMT progression in hypertensive subjects than in those who did not take medication, which was most prominent in the bifurcation segment. In addition, most predictors of IMT progression were identified in women in a gender-specific analysis. For plaque progression, age and gender were independent predictors.

Conclusions: The predictors of carotid atherosclerosis progression were gender and segment specific. The detection and control of hypertension may prevent atherosclerosis progression, particularly in women.

Key words: Intima-media thickness, Plaque, Cardiovascular risk factors, Progression, Atherosclerosis

\section{Introduction}

Atherosclerotic diseases are the leading cause of death in developed countries. Events because of atherosclerosis, such as cardiovascular disease, stroke, and myocardial infarction (MI), often occur without warning ${ }^{1)}$. The key factor for the primary prevention of

Address for correspondence: Hsiu-Fen Lin, Kaohsiung Medical University, 100 TzYou First Road, Kaohsiung City 807, Taiwan

E-mail: sflin@kmu.edu.tw

Received: September 20, 2015

Accepted for publication: December 14, 2015 atherosclerotic events is to identify asymptomatic individuals who are at a high risk ${ }^{2)}$ and then implement strategies that are directed at risk factors, which are known to be related to clinical events.

Carotid intima-media thickness (IMT) and plaque, which are surrogate markers of subclinical atherosclerosis, are considered to predict future MI and stroke ${ }^{3-6)}$, and changes in carotid IMT and plaque, which are noninvasively assessed by ultrasound, are being increasingly used as markers of atherosclerosis progression $^{7,8)}$. Several studies have investigated the predictors of carotid IMT and plaque progression ${ }^{9-15)}$. However, most of these longitudinal studies have 
focused on Caucasian populations, and only a few studies have investigated the predictors of atherosclerosis progression in Asian populations ${ }^{16-19)}$.

In a recent study on a Chinese population, the 5 -year change in systolic blood pressure was found to be associated with the incidence of carotid plaque and total plaque area progression ${ }^{19)}$. Moreover, in a Korean study on an elderly population ( $>60$ years of age), metabolic syndrome was found to be associated with the occurrence of new plaque and changes in common carotid artery (CCA) IMT after excluding subjects with thicker carotid IMT and carotid plaque at baseline ${ }^{18)}$. Another longitudinal study that was conducted in Japan also demonstrated the impact of metabolic syndrome on the progression of CCA IMT. The authors found that an increasing number of metabolic syndrome components was related to a larger annual IMT change, particularly in women ${ }^{17)}$. Carotid plaque and IMT may reflect the different biological aspects of atherogenesis with distinct relationships with cardiovascular risk factors ${ }^{20)}$. However, none of these studies on Asian populations explored the association of conventional cardiovascular risk factors with carotid IMT and plaque progression. In addition, no studies evaluated the association between vascular risk factors and carotid IMT progression at different segments in Asian patients.

\section{Aim}

This study aimed to investigate the predictors of the progression of segment-specific carotid IMT and plaque in a stroke- and MI-free Chinese population residing in Taiwan. In addition, we investigated the gender-specific predictors of carotid IMT and plaque progression.

\section{Methods}

\section{Subjects}

This prospective study was initiated in August $2006^{21)}$. The stroke- and MI-free participants were recruited through an advertisement that was posted in the Kaohsiung Medical University Hospital. From November 2008 to September 2014, 879 subjects who completed baseline surveys between August 2006 and December 2009 were contacted. The Kaohsiung Medical University Hospital Institutional Review Board approved the study, and all participants provided their written informed consent.

\section{Cardiovascular Risk Factors}

At baseline and follow-up visits, a self-administered structured questionnaire was provided to collect sociodemographic information, medical history, medication exposure, and smoking habits. Total cholesterol and glucose levels were measured from venous blood after fasting for at least $8 \mathrm{~h}$. A calibrated standard aneroid sphygmomanometer (Omron; Vernon Hills, Illinois) was used to measure blood pressure after resting for $5 \mathrm{~min}$. Two measurements of blood pressure were taken, and the average of these two measurements was used for analysis. Hypertension was defined as systolic or diastolic blood pressure of $\geq 140 / 90$ $\mathrm{mmHg}$ or the use of antihypertensive medications. Diabetes was defined as a fasting blood glucose level of $\geq 126 \mathrm{mg} / \mathrm{dl}$ or current treatment for diabetes. Hypercholesterolemia was defined as a serum total cholesterol level of $\geq 200 \mathrm{mg} / \mathrm{dl}$ or the use of lipidlowering medications. Participants were defined as smokers if they had ever smoked or were current smokers. Body mass index (BMI) was calculated as weight $(\mathrm{kg})$ divided by height squared $\left(\mathrm{m}^{2}\right)$.

\section{Carotid IMT and Plaque Measurement}

Carotid IMT was measured on enrollment and during the follow-up period for each participant by an experienced technician who was blinded to the patients' clinical data. Carotid IMT was assessed using a Philips HD 11 ultrasonography system that was equipped with a broadband linear array transducer. The transducer scanning direction was anterior oblique insonation while the subject was in the supine position. IMT was bilaterally visualized and measured at the plaque-free area of the CCA (10-20-mm proximal to the tip of the flow divider), carotid bifurcation (BIF) (tip of the flow divider extending 10-mm proxi$\mathrm{mal})$, and internal carotid artery (ICA) $(10-\mathrm{mm}$ proximal above BIF). If a carotid plaque was insonated, carotid IMT was measured outside the plaque portion. The far wall of the carotid IMT was analyzed using an off-line automatic computerized analysis system (Philips QLAB quantification software). Mean IMT values of both the right and left arteries from each segment were used for analysis. The annual progression of IMT ( $\mu \mathrm{m} /$ year$)$ was calculated as the difference between the IMT value that was measured at enrollment and during follow-up divided by the follow-up period in years. The intra-reader absolute IMT differences and standard deviations between the two readings were $0.01 \pm 0.01 \mathrm{~mm}$ in CCA, $0.03 \pm 0.04$ $\mathrm{mm}$ in BIF, and $0.02 \pm 0.01 \mathrm{~mm}$ in ICA.

A plaque was defined as an area of focal protrusion into the lumen at least $50 \%$ greater than the surrounding wall thickness. It was assessed by the same equipment that was used for the carotid IMT measurement. The presence of carotid plaques at 10 locations in the carotid arteries (proximal and distal CCA, 
BIF, ICA, and external carotid artery) was recorded. The total number of plaques was counted offline, and the changes in the number of plaques that were measured at enrollment and during follow-up were calculated. We defined plaque progression as an increase in the number of plaques by one or more during the follow-up compared with the number at enrollment. All ultrasound data were interpreted by a single neurologist (Dr. Hsiu-Fen Lin).

\section{Statistical Analysis}

Data were presented as mean \pm standard deviation or proportions. The $\chi^{2}$ test was used for categorical data and the t-test for continuous data. The independent relationships between baseline risk factors and IMT progression were assessed by multivariate linear regression analysis. We created dummy variables to group hypertension and hypercholesterolemia status as no disease, disease with treatment, and disease without treatment. Logistic regression analysis was conducted to investigate the predictive effect of baseline risk factors on the progression of plaque. We further analyzed these effects by gender. All analyses were performed using SPSS version 17.0 (SPSS Inc., Chicago, IL, USA). A two-tailed $p$ value of $<0.05$ was considered to be statistically significant.

\section{Results}

\section{Demographic Data}

Among the 879 eligible subjects, 98 were lost to follow-up, 60 refused to complete the second survey, and nine died. In total, 712 subjects were successfully followed up. Comparisons of the baseline characteristics between the patients who completed follow-up and those who dropped out are shown in Supplementary Table 1. The demographic and basic clinical characteristics of 712 subjects $(274$ men and 438 women) who completed the study are shown in Table 1. The age at enrollment was $54.7 \pm 9.4$ years, and the mean duration of follow-up was $4.3 \pm 0.9$ years. At baseline, more men had diabetes, a higher BMI, and smoked than women. Men also had a thicker IMT and higher rate of plaques compared with women at baseline and follow-up. Although there was no statistically significant difference in IMT progression between men and women, men had a higher rate of plaque progression.

\section{Predictors of Carotid IMT Progression}

Multivariate regression analysis was used to identify independent predictors of IMT progression (Table 2). We found a significantly inverse correlation between baseline IMT and its annual rate of progres- sion (Supplementary Table 2), which is consistent with previous reports ${ }^{11,12)}$. Therefore, in addition to conventional risk factors at baseline (i.e., age, gender, diabetes, hypertension, hypercholesterolemia, smoking, BMI, antihypertensive and lipid-lowering medications), baseline IMT was selected as a covariate. We found that the statistical significance of conventional risk factors varied in different carotid segments. Age and smoking were independent predictors of CCA IMT progression (adjusted $p<0.001$ and $p=0.045$, respectively). Age and hypertension were independent predictors of BIF IMT progression (adjusted $p<0.001$ and $p=0.033$, respectively), while the use of antihypertensive medication could slow down the progression (adjusted $p<0.001$ ). There were no significant predictors of ICA IMT progression.

\section{Relationship between Hypertension Treatment and IMT Progression}

Because hypertension and the use of antihypertensive medication at baseline were related to IMT progression, we further investigated the relationship between antihypertensive treatment and IMT progression in hypertensive subjects. As shown in Fig. 1, the rate of annual IMT progression was slower in patients who took medication than in those who did not in all segments of IMT (9.60 vs. $10.86 \mu \mathrm{m} /$ year in CCA; 12.00 vs. $25.76 \mu \mathrm{m} /$ year in BIF; 11.30 vs. $14.63 \mu \mathrm{m} /$ year in ICA). The difference was most prominent in the BIF segment $(p=0.015)$.

\section{Differences between Genders in Predicting IMT Progression}

To investigate gender-specific predictors of IMT progression, further multivariate regression analysis was performed (Table 3). In women, age and smoking were statistically significant predictors of CCA IMT progression (adjusted $p<0.001$ and $p=0.011$, respectively). Age, hypertension, and antihypertensive medication were associated with BIF IMT progression (adjusted $p<0.001, p=0.005$, and $p=0.002$, respectively). The use of antihypertensive medication was associated with slower progression in the ICA IMT segment (adjusted $p=0.001$ ). However, in men, there were no associations between any cardiovascular risk factors and IMT progression except for age in predicting CCA and BIF IMT progression $(p=0.041$ and $p$ $<0.001$, respectively).

\section{Predictors of Plaque Progression}

Age was a predictor of carotid plaque progression (Table 4), and the risk of plaque progression was 1.05 -fold each year (adjusted $p<0.001$ ). In addition, gender was also associated with plaque progression. 
Table 1. Demographic features of the study participants

\begin{tabular}{|c|c|c|c|c|}
\hline & All $(N=712)$ & Women $(N=438)$ & $\operatorname{Men}(N=274)$ & $P$ value \\
\hline \multicolumn{5}{|l|}{ Baseline } \\
\hline Age (years) & $54.7 \pm 9.4$ & $53.9 \pm 9.1$ & $55.9 \pm 9.7$ & $0.007^{* *}$ \\
\hline Diabetes & $64(9.0)$ & $21(4.8)$ & $43(15.7)$ & $<0.001^{* *}$ \\
\hline Hypertension & $216(30.3)$ & $123(28.1)$ & $93(33.9)$ & 0.099 \\
\hline Using antihypertensive medication & $165(76.4)$ & $90(73.2)$ & $75(80.6)$ & 0.107 \\
\hline Hypercholesterolemia & $157(22.1)$ & $91(20.8)$ & $66(24.1)$ & 0.308 \\
\hline Using lipid-lowering medication & $84(53.5)$ & $42(46.2)$ & $42(63.6)$ & 0.054 \\
\hline Ever and current smoking & $114(16.0)$ & $10(2.3)$ & $104(38.0)$ & $<0.001^{* *}$ \\
\hline BMI $\left(\mathrm{kg} / \mathrm{m}^{2}\right)$ & $24.3 \pm 3.2$ & $23.7 \pm 3.1$ & $25.3 \pm 3.1$ & $<0.001^{* *}$ \\
\hline \multicolumn{5}{|l|}{ Baseline IMT(mm) } \\
\hline CCA & $0.62 \pm 0.15$ & $0.59 \pm 0.12$ & $0.67 \pm 0.17$ & $<0.001^{* *}$ \\
\hline BIF & $0.65 \pm 0.13$ & $0.63 \pm 0.12$ & $0.68 \pm 0.14$ & $<0.001^{* *}$ \\
\hline ICA & $0.50 \pm 0.09$ & $0.48 \pm 0.08$ & $0.53 \pm 0.09$ & $<0.001^{* *}$ \\
\hline \multicolumn{5}{|l|}{ Follow up IMT $(\mathrm{mm})$} \\
\hline CCA & $0.67 \pm 0.15$ & $0.64 \pm 0.13$ & $0.72 \pm 0.17$ & $<0.001^{* *}$ \\
\hline $\mathrm{BIF}$ & $0.72 \pm 0.14$ & $0.70 \pm 0.13$ & $0.76 \pm 0.15$ & $<0.001^{* *}$ \\
\hline ICA & $0.54 \pm 0.10$ & $0.53 \pm 0.10$ & $0.57 \pm 0.10$ & $<0.001^{* *}$ \\
\hline Baseline plaque presence & $242(34.0)$ & $128(29.2)$ & $114(41.6)$ & $0.001^{* *}$ \\
\hline Follow-up plaque presence & $301(42.3)$ & $159(36.3)$ & $142(51.8)$ & $<0.001^{* *}$ \\
\hline \multicolumn{5}{|l|}{ Annual IMT progression rate $(\mu \mathrm{m} /$ year $)$} \\
\hline CCA & $11.82 \pm 19.95$ & $11.72 \pm 16.99$ & $11.99 \pm 24.01$ & 0.873 \\
\hline BIF & $17.39 \pm 28.94$ & $17.31 \pm 27.72$ & $17.50 \pm 30.87$ & 0.931 \\
\hline ICA & $10.37 \pm 20.13$ & $10.42 \pm 19.38$ & $10.27 \pm 21.32$ & 0.923 \\
\hline Progression of plaque & $167(23.5)$ & $84(19.2)$ & $83(30.3)$ & $0.001^{* *}$ \\
\hline
\end{tabular}

$p$ values comparing men and women using the Student's $t$ test or chi-squared test.

Data are shown as mean \pm SD for quantitative variables and $n(\%)$ for qualitative variables.

Abbreviations: IMT, intima-media thickness; CCA, common carotid artery; BIF, bifurcation; ICA, internal carotid artery; BMI, body mass index

${ }^{*} p<0.05,{ }^{* *} p<0.01$

Men had a 1.62-fold higher risk of plaque progression than women (adjusted $p=0.039$ ).

\section{Discussion}

In this prospective follow-up study, the predictors of carotid IMT progression were gender and segment specific. Age was a risk factor for the progression of CCA and BIF IMT in both genders, while smoking and hypertension were the predictors of CCA and BIF IMT progression only in women. Antihypertensive medication could slow down the rate of IMT progression, particularly in women. Therefore, our findings may imply the importance of blood pressure control in hypertensive subjects to prevent the progression of atherosclerosis, particularly in women.

Ethnic differences have been reported in the risk factors for cardiovascular disease and atherosclerosis progression $^{22-24)}$. The Northern Manhattan Stroke study demonstrated that the effect of hypertension and diabetes on the risk of stroke was greater among blacks and Caribbean Hispanics than among whites; whereas the number of strokes that were attributable to atrial fibrillation was higher in whites than in blacks $^{23)}$. Results from the Multi-Ethnic Study of Atherosclerosis also demonstrated that the effect of diabetes was strongest in blacks and weakest in Hispanics in coronary artery calcium progression ${ }^{22)}$. Therefore, the risk factors and their effect on the progression of carotid atherosclerosis may vary between different ethnic groups.

Few studies have evaluated the predictors of carotid atherosclerosis progression in Asian patients ${ }^{16-19)}$, and most of these studies have focused on special groups (diabetes mellitus, elderly) or on specific carotid atherosclerotic parameters (IMT or plaque). It is known that plaque and IMT may represent different phenotypes of atherosclerosis with different relationships to cardiovascular risk factors and clinical vascular events ${ }^{10,25}$. IMT changes reflect an 
Table 2. Association between risk factors and carotid IMT progression in a multivariate regression model

\begin{tabular}{|c|c|c|c|}
\hline \multirow[b]{2}{*}{ Risk factors at baseline } & \multicolumn{3}{|c|}{ IMT progression } \\
\hline & CCA & $\mathrm{BIF}$ & ICA \\
\hline Age & $\begin{array}{l}\beta=0.183 \\
p<0.001^{* *}\end{array}$ & $\begin{array}{l}\beta=0.216 \\
p<0.001^{* *}\end{array}$ & $\begin{array}{l}\beta=0.002 \\
p=0.964\end{array}$ \\
\hline Gender & $\begin{array}{l}\beta=0.014 \\
p=0.759\end{array}$ & $\begin{array}{l}\beta=0.036 \\
p=0.393\end{array}$ & $\begin{array}{l}\beta=0.081 \\
p=0.070\end{array}$ \\
\hline Diabetes & $\begin{array}{l}\beta=0.065 \\
p=0.107\end{array}$ & $\begin{array}{l}\beta=-0.014 \\
p=0.706\end{array}$ & $\begin{array}{l}\beta=0.041 \\
p=0.291\end{array}$ \\
\hline Hypertension & $\begin{array}{l}\beta=-0.083 \\
p=0.074\end{array}$ & $\begin{array}{l}\beta=-0.092 \\
p=0.033^{*}\end{array}$ & $\begin{array}{l}\beta=0.043 \\
p=0.340\end{array}$ \\
\hline Hypercholesterolemia & $\begin{array}{l}\beta=-0.061 \\
p=0.250\end{array}$ & $\begin{array}{l}\beta=-0.073 \\
p=0.142\end{array}$ & $\begin{array}{l}\beta=-0.071 \\
p=0.165\end{array}$ \\
\hline Ever and current smoking & $\begin{array}{l}\beta=0.089 \\
p=0.045^{*}\end{array}$ & $\begin{array}{l}\beta=0.067 \\
p=0.106\end{array}$ & $\begin{array}{l}\beta=0.035 \\
p=0.414\end{array}$ \\
\hline BMI & $\begin{array}{l}\beta=0.030 \\
p=0.456\end{array}$ & $\begin{array}{l}\beta=0.012 \\
p=0.756\end{array}$ & $\begin{array}{l}\beta=0.022 \\
p=0.564\end{array}$ \\
\hline Baseline IMT & $\begin{array}{l}\beta=-0.289 \\
p<0.001^{* *}\end{array}$ & $\begin{array}{l}\beta=-0.460 \\
p<0.001^{* *}\end{array}$ & $\begin{array}{l}\beta=-0.380 \\
p<0.001^{* *}\end{array}$ \\
\hline Antihypertensive medication & $\begin{array}{l}\beta=-0.061 \\
p=0.164\end{array}$ & $\begin{array}{l}\beta=-0.149 \\
p<0.001^{* *}\end{array}$ & $\begin{array}{l}\beta=-0.065 \\
p=0.120\end{array}$ \\
\hline Lipid-lowering medication & $\begin{array}{l}\beta=-0.002 \\
p=0.975\end{array}$ & $\begin{array}{l}\beta=-0.012 \\
p=0.794\end{array}$ & $\begin{array}{l}\beta=-0.042 \\
p=0.389\end{array}$ \\
\hline
\end{tabular}

Abbreviations: IMT, intima-media thickness; CCA, common carotid artery; BIF, bifurcation; ICA, internal carotid artery; BMI, body mass index

${ }^{*} p<0.05,{ }^{* *} p<0.01$

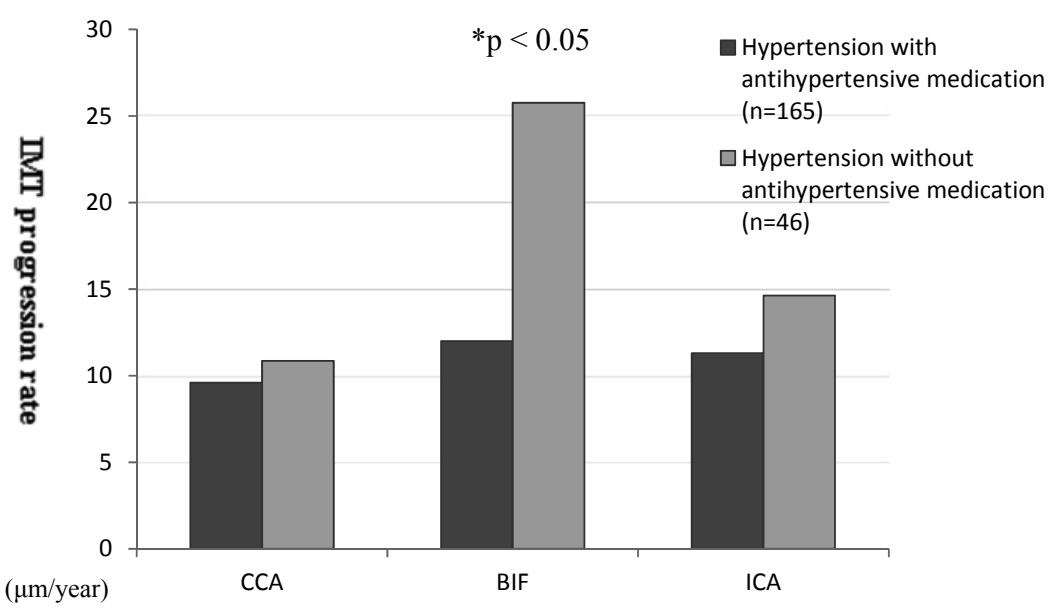

Fig. 1. Carotid IMT progression rate of hypertension treatment status

$p$ value comparing the IMT progression rate between those with hypertension using and not using antihypertensive medication using the Student's $t$-test.

Abbreviations: IMT, intima-media thickness; CCA, common carotid artery; BIF, bifurcation; ICA, internal carotid artery 
Table 3. Association between risk factors and carotid IMT progression by gender

\begin{tabular}{|c|c|c|c|c|c|c|}
\hline \multirow{2}{*}{ Risk factors at baseline } & \multicolumn{6}{|c|}{ IMT progression } \\
\hline & Women & Men & Women & Men & Women & Men \\
\hline Age & $\begin{array}{l}\beta=0.207 \\
p<0.001^{* *}\end{array}$ & $\begin{array}{l}\beta=0.160 \\
p=0.041^{*}\end{array}$ & $\begin{array}{l}\beta=0.196 \\
p<0.001^{* *}\end{array}$ & $\begin{array}{l}\beta=0.251 \\
p<0.001^{* *}\end{array}$ & $\begin{array}{l}\beta=-0.035 \\
p=0.485\end{array}$ & $\begin{array}{l}\beta=0.031 \\
p=0.648\end{array}$ \\
\hline Hypertension & $\begin{array}{l}\beta=-0.070 \\
p=0.244\end{array}$ & $\begin{array}{l}\beta=-0.098 \\
p=0.190\end{array}$ & $\begin{array}{l}\beta=-0.157 \\
p=0.005^{* *}\end{array}$ & $\begin{array}{l}\beta=-0.010 \\
p=0.886\end{array}$ & $\begin{array}{l}\beta=0.001 \\
p=0.991\end{array}$ & $\begin{array}{l}\beta=0.111 \\
p=0.127\end{array}$ \\
\hline Hypercholesterolemia & $\begin{array}{l}\beta=-0.072 \\
p=0.304\end{array}$ & $\begin{array}{l}\beta=-0.028 \\
p=0.734\end{array}$ & $\begin{array}{l}\beta=-0.067 \\
p=0.307\end{array}$ & $\begin{array}{l}\beta=-0.067 \\
p=0.381\end{array}$ & $\begin{array}{l}\beta=-0.073 \\
p=0.273\end{array}$ & $\begin{array}{l}\beta=-0.073 \\
p=0.365\end{array}$ \\
\hline BMI & $\begin{array}{l}\beta=0.076 \\
p=0.126\end{array}$ & $\begin{array}{l}\beta=-0.032 \\
p=0.642\end{array}$ & $\begin{array}{l}\beta=0.027 \\
p=0.557\end{array}$ & $\begin{array}{l}\beta=0.001 \\
p=0.993\end{array}$ & $\begin{array}{l}\beta=0.079 \\
p=0.090\end{array}$ & $\begin{array}{l}\beta=-0.073 \\
p=0.269\end{array}$ \\
\hline Baseline IMT & $\begin{array}{l}\beta=-0.259 \\
p<0.001^{* *}\end{array}$ & $\begin{array}{l}\beta=-0.301 \\
p<0.001^{* *}\end{array}$ & $\begin{array}{l}\beta=-0.423 \\
p<0.001\end{array}$ & $\begin{array}{l}\beta=-0.482 \\
p<0.001^{* *}\end{array}$ & $\begin{array}{l}\beta=-0.376 \\
p<0.001^{* *}\end{array}$ & $\begin{array}{l}\beta=-0.362 \\
p<0.001^{* *}\end{array}$ \\
\hline Antihypertensive medication & $\begin{array}{l}\beta=-0.109 \\
p=0.052\end{array}$ & $\begin{array}{l}\beta=0.016 \\
p=0.822\end{array}$ & $\begin{array}{l}\beta=-0.166 \\
p=0.002^{* *}\end{array}$ & $\begin{array}{l}\beta=-0.120 \\
p=0.064\end{array}$ & $\begin{array}{l}\beta=-0.176 \\
p=0.001^{* *}\end{array}$ & $\begin{array}{l}\beta=0.098 \\
p=0.149\end{array}$ \\
\hline Lipid-lowering medication & $\begin{array}{l}\beta=0.035 \\
p=0.611\end{array}$ & $\begin{array}{l}\beta=-0.020 \\
p=0.803\end{array}$ & $\begin{array}{l}\beta=-0.016 \\
p=0.807\end{array}$ & $\begin{array}{l}\beta=-0.002 \\
p=0.974\end{array}$ & $\begin{array}{l}\beta=-0.038 \\
p=0.553\end{array}$ & $\begin{array}{l}\beta=-0.048 \\
p=0.528\end{array}$ \\
\hline
\end{tabular}

Abbreviations: IMT, intima-media thickness; CCA, common carotid artery; BIF, bifurcation; ICA, internal carotid artery; BMI, body mass index ${ }^{*} p<0.05,{ }^{* *} p<0.01$

Table 4. Predictors of carotid plaque progression

\begin{tabular}{lcc}
\hline Risk factors at baseline & Odds Ratio (95\% CI) & $p$ value \\
\hline Age & $1.05(1.02-1.07)$ & $<0.001^{* *}$ \\
Gender(Men/Women) & $1.62(1.03-2.55)$ & $0.039^{*}$ \\
Diabetes mellitus & $1.43(0.76-2.69)$ & 0.270 \\
Hypertension status & & \\
$\quad$ No hypertension & 1.00 & 0.088 \\
$\quad$ Hypertension with antihypertensive medication & $1.51(0.94-2.43)$ & 0.179 \\
$\quad$ Hypertension without antihypertensive medication & $1.64(0.78-3.39)$ & \\
Hypercholesterolemia status & & 0.313 \\
$\quad$ No hypercholesterolemia & 1.00 & 0.588 \\
$\quad$ Hypercholesterolemia with lipid-lowering medication & $1.34(0.76-2.38)$ & 0.173 \\
$\quad$ Hypercholesterolemia without lipid-lowering medication & $1.18(0.65-2.16)$ & 0.146 \\
Ever and current smoking & $1.46(0.85-2.50)$ & 0.870 \\
BMI & $0.95(0.90-1.02)$ & 0.098 \\
Follow up duration (years) & $0.98(0.79-1.22)$ & \\
Baseline plague presence & $0.70(0.46-1.07)$ &
\end{tabular}

Abbreviations: BMI, body mass index

${ }^{*} p<0.05,{ }^{* *} p<0.01$ 
adaptive process and represent an early carotid atherosclerosis, while plaque formation may reflect a more significant alteration in vessel walls and represent an estimate of more advanced status ${ }^{26)}$. Thus, these two aspects of atherosclerosis reflect different biological aspects of atherogenesis. By evaluating both the early and late stages of carotid atherosclerosis progression and conventional cardiovascular risk factors, our study may provide important clinical information.

In agreement with previous studies ${ }^{10,13-15,19)}$, the most consistent predictors of carotid IMT and plaque progression in this study were age and hypertension. Antihypertensive medication use may be the strongest modifiable predictor of slowing IMT progression over time $^{27,28)}$, and may be able to further prevent the development of stroke and coronary heart disease. In this study, we demonstrated that antihypertensive medication was associated with slowing carotid IMT progression. Furthermore, its effect on carotid IMT progression differed by a segment, which has not been reported before.

Few studies have reported on the association between vascular risk factors and carotid IMT progression at different segments ${ }^{11,13,14)}$,and most previous studies have only focused on the progression in the CCA IMT segment ${ }^{9,10,12,15)}$. Theoretically, these segments histologically differ and their walls are differentially exposed to turbulent flow ${ }^{29)}$. Therefore, it is reasonable that IMT progression is segment specific and governed by different cardiovascular risk factors. The Carotid Atherosclerosis Progression Study reported that the predictors of ICA IMT progression were age, male gender, hypertension, diabetes, and currently smoking and that age and currently smoking were predictors of IMT progression at BIF ${ }^{13)}$. In the Bogalusa Heart Study, Nguyen et al. also found different predictors of CCA, BIF, and ICA IMT progression in young adults ${ }^{14)}$. However, our study is the first to demonstrate different risk predictors for all segments of carotid IMT progression in an Asian population. The identification of these specific risk markers may be important with regard to the pathophysiology and early prevention of IMT progression.

Coronary artery disease in women lags behind men by $10-15$ years. This delay is believed to be caused by the protective effect of estrogen on coronary atherosclerosis ${ }^{30)}$. The average age of women in our study population was 54 years at baseline, with up to $67 \%$ having had menopause, which has been reported to have unfavorable effects on lipid metabolism, and increased incidence, mortality and morbidity due to cardiovascular disease as compared with premenopausal control ${ }^{31-33)}$. A previous study reported a ceiling effect in arterial stiffness ${ }^{34)}$ and that men have a thicker IMT, which could possibly explain why most of the underlying risk factors for IMT progression were identified in women rather than in men in this study.

There are strengths and limitations to this study. Carotid IMT and plaque were separately measured, and thus, atherosclerosis progression was more thoroughly evaluated than in previous Asian studies. Measuring the progression of IMT is more difficult than making a single measurement because random measurement errors at baseline and follow-up can accumulate. However, in this study, all measurements were performed by a single experienced sonographer, and the IMT measurement was performed by a single neurologist, which would counteract the inherent measurement errors. In this study, we did not measure IMT in a specific cardiac phase. However, the Chinese population has the smallest changes in IMT during the cardiac cycle as compared with the non-Hispanic whites ${ }^{35)}$, which may minimize the impact of the cardiac phase to IMT data in this study. The subjects enrolled in this study were followed up for $>2$ years. The timing of the second survey was in accordance with the participants' will. Therefore, the follow-up period was heterogeneous. However, annual IMT progression could overcome this limitation. The other potential limitation is that some clinical profiles differed between those who dropped out and those who completed follow-up. Those who dropped out had a higher prevalence of diabetes, hypertension, and hypercholesterolemia, which could limit the conclusiveness of the findings.

\section{Conclusion}

In conclusion, there were differences in the gender and segmental predictors of carotid atherosclerosis progression in our Taiwan Chinese population. In women, hypertension was more strongly associated with carotid IMT progression and the use of antihypertensive medication protected against carotid IMT progression. Therefore, the detection and control of hypertension may prevent atherosclerosis progression and may reduce cardiovascular disease, particularly in women.

\section{Acknowledgments}

This work was supported by grants from the Ministry of Science and Technology (Taiwan, R. O.C.103-2314-B-037-029), Kaohsiung Medical University Hospital intramural grants (KMUH1011R55). 


\section{Conflicts of Interest}

None.

\section{References}

1) Greenland P, Abrams J, Aurigemma GP, Bond MG, Clark LT, Criqui MH, Crouse JR, 3rd, Friedman L, Fuster V, Herrington DM, Kuller LH, Ridker PM, Roberts WC, Stanford W, Stone N, Swan HJ, Taubert KA, Wexler L: Prevention Conference V: Beyond secondary prevention: identifying the high-risk patient for primary prevention: noninvasive tests of atherosclerotic burden: Writing Group III. Circulation, 2000; 101: E16-E22

2) Smith SC, Jr., Greenland P, Grundy SM: AHA Conference Proceedings. Prevention conference V: Beyond secondary prevention: Identifying the high-risk patient for primary prevention: executive summary. American Heart Association. Circulation, 2000; 101: 111-116

3) Simons PC, Algra A, Bots ML, Grobbee DE, van der Graaf Y: Common carotid intima-media thickness and arterial stiffness: indicators of cardiovascular risk in highrisk patients. The SMART Study (Second Manifestations of ARTerial disease). Circulation, 1999; 100: 951-957

4) O'Leary DH, Polak JF, Kronmal RA, Manolio TA, Burke GL, Wolfson SK, Jr.: Carotid-artery intima and media thickness as a risk factor for myocardial infarction and stroke in older adults. Cardiovascular Health Study Collaborative Research Group. N Engl J Med, 1999; 340: 14-22

5) Lorenz MW, Markus HS, Bots ML, Rosvall M, Sitzer M: Prediction of clinical cardiovascular events with carotid intima-media thickness: a systematic review and metaanalysis. Circulation, 2007; 115: 459-467

6) Plichart M, Celermajer DS, Zureik M, Helmer C, Jouven X, Ritchie K, Tzourio C, Ducimetiere P, Empana JP: Carotid intima-media thickness in plaque-free site, carotid plaques and coronary heart disease risk prediction in older adults. The Three-City Study. Atherosclerosis, 2011; 219: 917-924

7) Polak JF, Pencina MJ, O'Leary DH, D'Agostino RB: Common carotid artery intima-media thickness progression as a predictor of stroke in multi-ethnic study of atherosclerosis. Stroke, 2011; 42: 3017-3021

8) Hirano M, Nakamura T, Kitta Y, Takishima I, Deyama J, Kobayashi T, Fujioka D, Saito Y, Watanabe K, Watanabe Y, Kawabata K, Obata JE, Kugiyama K: Short-term progression of maximum intima-media thickness of carotid plaque is associated with future coronary events in patients with coronary artery disease. Atherosclerosis, 2011; 215: 507-512

9) Chambless LE, Folsom AR, Davis V, Sharrett R, Heiss G, Sorlie P, Szklo M, Howard G, Evans GW: Risk factors for progression of common carotid atherosclerosis: the Atherosclerosis Risk in Communities Study, 1987-1998. Am J Epidemiol, 2002; 155: 38-47

10) Herder M, Johnsen SH, Arntzen KA, Mathiesen EB: Risk factors for progression of carotid intima-media thickness and total plaque area: a 13-year follow-up study: the Tromso Study. Stroke, 2012; 43: 1818-1823
11) Johnson HM, Douglas PS, Srinivasan SR, Bond MG, Tang R, Li S, Chen W, Berenson GS, Stein JH: Predictors of carotid intima-media thickness progression in young adults: the Bogalusa Heart Study. Stroke, 2007; 38: 900905

12) Koskinen J, Kahonen M, Viikari JS, Taittonen L, Laitinen T, Ronnemaa T, Lehtimaki T, Hutri-Kahonen N, Pietikainen M, Jokinen E, Helenius H, Mattsson N, Raitakari OT, Juonala M: Conventional cardiovascular risk factors and metabolic syndrome in predicting carotid intimamedia thickness progression in young adults: the cardiovascular risk in young Finns study. Circulation, 2009; 120: 229-236

13) Mackinnon AD, Jerrard-Dunne P, Sitzer M, Buehler A, von Kegler S, Markus HS: Rates and determinants of sitespecific progression of carotid artery intima-media thickness: the carotid atherosclerosis progression study. Stroke, 2004; 35: 2150-2154

14) Nguyen QM, Toprak A, Xu JH, Srinivasan SR, Chen W, Berenson GS: Progression of segment-specific carotid artery intima-media thickness in young adults (from the Bogalusa Heart Study). Am J Cardiol, 2011; 107: 114119

15) van der Meer IM, Iglesias del Sol A, Hak AE, Bots ML, Hofman A, Witteman JC: Risk factors for progression of atherosclerosis measured at multiple sites in the arterial tree: the Rotterdam Study. Stroke, 2003; 34: 2374-2379

16) Yamasaki Y, Kodama M, Nishizawa H, Sakamoto K, Matsuhisa M, Kajimoto Y, Kosugi K, Shimizu Y, Kawamori R, Hori M: Carotid intima-media thickness in Japanese type 2 diabetic subjects: predictors of progression and relationship with incident coronary heart disease. Diabetes Care, 2000; 23: 1310-1315

17) Matoba $Y$, Inoguchi $T$, Suzuki S, Nasu S, Hashimoto T, Yanase T, Nawata H, Takayanagi R: Impact of metabolic syndrome on the progression of Intima-Media Thickening in Japanese--a follow-up study. Diabetes Res Clin Pract, 2009; 86: e50-e53

18) Jung JM, Young Kwon D, Han C, Park MH: Metabolic syndrome and early carotid atherosclerosis in the elderly. J Atheroscler Thromb, 2014; 21: 435-444

19) Xie W, Liu J, Wang W, Wang M, Li Y, Sun J, Liu J, Qi Y, Zhao F, Zhao D: Five-year change in systolic blood pressure is independently associated with carotid atherosclerosis progression: a population-based cohort study. Hypertens Res, 2014; 37: 960-965

20) Al-Shali K, House AA, Hanley AJG, Khan HMR, Harris SB, Mamakeesick M, Zinman B, Fenster A, Spence JD, Hegele RA: Differences between carotid wall morphological phenotypes measured by ultrasound in one, two and three dimensions. Atherosclerosis, 2005; 178: 319-325

21) Lin HF, Liu CK, Liao YC, Lin RT, Chen CS, Juo SH: The risk of the metabolic syndrome on carotid thickness and stiffness: sex and age specific effects. Atherosclerosis, 2010; 210: 155-159

22) Kronmal RA, McClelland RL, Detrano R, Shea S, Lima JA, Cushman M, Bild DE, Burke GL: Risk factors for the progression of coronary artery calcification in asymptomatic subjects: results from the Multi-Ethnic Study of Atherosclerosis (MESA). Circulation, 2007; 115: 2722-2730

23) Sacco RL, Boden-Albala B, Abel G, Lin IF, Elkind M, 
Hauser WA, Paik MC, Shea S: Race-ethnic disparities in the impact of stroke risk factors: the northern Manhattan stroke study. Stroke, 2001; 32: 1725-1731

24) Li S, Chen W, Srinivasan SR, Tang R, Bond MG, Berenson GS: Race (black-white) and gender divergences in the relationship of childhood cardiovascular risk factors to carotid artery intima-media thickness in adulthood: the Bogalusa Heart Study. Atherosclerosis, 2007; 194: 421425

25) Al-Shali K, House AA, Hanley AJ, Khan HM, Harris SB, Mamakeesick M, Zinman B, Fenster A, Spence JD, Hegele RA: Differences between carotid wall morphological phenotypes measured by ultrasound in one, two and three dimensions. Atherosclerosis, 2005; 178: 319-325

26) Homma S, Hirose N, Ishida H, Ishii T, Araki G: Carotid plaque and intima-media thickness assessed by b-mode ultrasonography in subjects ranging from young adults to centenarians. Stroke, 2001; 32: 830-835

27) Wang JG, Staessen JA, Li Y, Van Bortel LM, Nawrot T, Fagard R, Messerli FH, Safar M: Carotid intima-media thickness and antihypertensive treatment: a meta-analysis of randomized controlled trials. Stroke, 2006; 37: 19331940

28) Tattersall MC, Gassett A, Korcarz CE, Gepner AD, Kaufman JD, Liu KJ, Astor BC, Sheppard L, Kronmal RA, Stein JH: Predictors of carotid thickness and plaque progression during a decade: the Multi-Ethnic Study of Atherosclerosis. Stroke, 2014; 45: 3257-3262
29) Espeland MA, Tang R, Terry JG, Davis DH, Mercuri M, Crouse JR, 3rd: Associations of risk factors with segmentspecific intimal-medial thickness of the extracranial carotid artery. Stroke, 1999; 30: 1047-1055

30) Burke AP, Farb A, Malcom G, Virmani R: Effect of menopause on plaque morphologic characteristics in coronary atherosclerosis. Am Heart J, 2001; 141: S58-S62

31) Cid MC, Schnaper HW, Kleinman HK: Estrogens and the vascular endothelium. Ann N Y Acad Sci, 2002; 966: 143-157

32) Matthews KA, Meilahn E, Kuller LH, Kelsey SF, Caggiula AW, Wing RR: Menopause and risk factors for coronary heart disease. N Engl J Med, 1989; 321: 641-646

33) Tremollieres FA, Pouilles JM, Cauneille C, Ribot C: Coronary heart disease risk factors and menopause: a study in 1684 French women. Atherosclerosis, 1999; 142: 415423

34) Gepner AD, Korcarz CE, Colangelo LA, Hom EK, Tattersall MC, Astor BC, Kaufman JD, Liu K, Stein JH: Longitudinal effects of a decade of aging on carotid artery stiffness: the multiethnic study of atherosclerosis. Stroke, 2014; 45: 48-53

35) Polak JF, Johnson C, Harrington A, Wong Q, O’Leary $\mathrm{DH}$, Burke G, Yanez ND: Changes in carotid intimamedia thickness during the cardiac cycle: the multi-ethnic study of atherosclerosis. Journal of the American Heart Association, 2012; 1: e001420 
Supplementary Table 1. Comparison of baseline characteristic between those who did and did not complete the study

\begin{tabular}{lccl}
\hline & Participants $(N=712)$ & Dropped out $(N=167)$ & $P$ value \\
\hline Age (years) & $54.7 \pm 9.4$ & $53.6 \pm 15.4$ & 0.251 \\
Gender-Men & $38.5 \%$ & $39.5 \%$ & 0.804 \\
Diabetes & $9.1 \%$ & $15.6 \%$ & $0.014^{*}$ \\
Hypertension & $30.5 \%$ & $41.3 \%$ & $0.007^{* *}$ \\
Hypercholesterolemia & $22.3 \%$ & $30.5 \%$ & $0.025^{*}$ \\
Ever and current smoking & $16.7 \%$ & $19.2 \%$ & 0.448 \\
BMI $\left(\mathrm{kg} / \mathrm{m}^{2}\right)$ & $24.7 \pm 3.4$ & $25.1 \pm 3.8$ & 0.177 \\
\hline
\end{tabular}

$p$ values comparing the participants and those who dropped out using the Student's $t$ test or chi-squared test.

Data are shown as mean \pm SD for quantitative variables and $n(\%)$ for qualitative variables.

Abbreviations: BMI, body mass index

${ }^{*} p<0.05,{ }^{* *} p<0.01$

Supplementary Table 2. Pearson's correlation between baseline carotid IMT and IMT progression

\begin{tabular}{llll}
\hline & \multicolumn{3}{c}{ IMT progression } \\
\cline { 2 - 4 } Baseline IMT & \multicolumn{1}{c}{ CCA } & \multicolumn{1}{c}{ BIF } & \multicolumn{1}{c}{ ICA } \\
\hline CCA & $r=-0.23, p=<0.001^{* *}$ & $r=-0.09, p=0.016^{*}$ & $r=-0.02, p=0.669$ \\
BIF & $r=-0.03, p=0.447$ & $r=-0.41, p=<0.001^{* *}$ & $r=-0.07, p=0.068$ \\
ICA & $r=0.07, p=0.072$ & $r=-0.04, p=0.365$ & $r=-0.37, p=<0.001^{* *}$ \\
\hline
\end{tabular}

Abbreviations: IMT, intima-media thickness; CCA, common carotid artery; BIF, bifurcation; ICA, internal carotid artery ${ }^{*} p<0.05,{ }^{* *} p<0.01$ 